\title{
A PEDAGOGIA LIBERTADORA DE FREIRE COMO POSSIBILIDADE DE EMPODERAMENTO DA MULHER NA EJA
}

Rosely de Oliveira Macário ${ }^{1}$

Linduarte Pereira Rodrigues ${ }^{2}$

\section{RESUMO}

Este trabalho apresenta o resultado de um estudo teórico que compõe parte de uma pesquisa desenvolvida na Educação de Jovens e Adultos (EJA) e consiste em discutir práticas de leitura voltadas ao empoderamento das mulheres/estudantes vinculadas ao Ensino Fundamental das séries iniciais ( $1^{\circ}$ ao $5^{\circ}$ ano) da EJA. A pesquisa se justifica pela necessidade de analisar alguns estudos já realizados por pesquisadores nesta modalidade de ensino, sustentados à luz dos pressupostos de Freire, no intuito de refletir sobre as práticas educativas que se configuram no universo escolar da EJA. Pautados na metodologia da pesquisa exploratória, do tipo bibliográfica, os resultados desta investigação apontam a necessidade de aproximação docente com a pedagogia do diálogo, da escuta, bem como entre as estudantes, frente à necessidade de práticas de leitura ao encontro do empoderamento das mulheres para além dos muros da escola. Sinalizam ainda para um ensino da língua materna ao encontro das mulheres em situação de diversidade, na busca pelo desejo unânime de aprender a ler/escrever, indo além do processo

\footnotetext{
${ }^{1}$ Doutora em Educação pela Universidade do Estado do Rio de Janeiro (UERJ). Professora do Departamento de Educação da Universidade Estadual da Paraíba (UEPB). Membro do grupo de pesquisa - Teorias do sentido: discursos e significações (TEOSSENO-CNPQUEPB). ORCID: https://orcid.org/0000-0002-3810-5241. E-mail: roselymacario@gmail.com.

${ }^{2}$ Doutor em Linguística e Mestre em Letras pela Universidade Federal da Paraíba (UFPB). Professor do Departamento de Letras e Artes (DLA) e do Programa de Pós-Graduação em Formação de Professores (PPGFP) da Universidade Estadual da Paraíba. Líder do grupo de pesquisa - Teorias do sentido: discursos e significações (TEOSSENO-CNPQUEPB). ORCID: https://orcid.org/0000-0002-9748-179X. E-mail: linduartepr@gmail.com.
} 
mecânico de decodificação, diante dos desafios colocados para a educação emancipadora na sociedade contemporânea.

Palavras-chave: Educação emancipadora. Leitura. Empoderamento. Diversidade. EJA.

\section{FREIRE'S LIBERATING PEDAGOGY AS A POSSIBILITY OF WOMEN'S EMPOWERMENT IN EJA}

\section{ABSTRACT}

This work presents the result of a theoretical study that is part of a research developed in the Education of Youth and Adults (EJA) and consists of discussing reading practices aimed at the empowerment of women/students linked to elementary school in the early grades (1st to 5th year) of EJA. The research is justified by the need to analyze some studies already carried out by researchers in this modality of teaching, supported in the light of Freire's assumptions, in order to reflect on the educational practices that are configured in the EJA school universe. Based on the methodology of exploratory research, of the bibliographic type, the results of this investigation point to the need to bring teachers closer to the pedagogy of dialogue, listening, as well as among students, given the need for reading practices to meet the empowerment of women to beyond the school walls. They also point to a teaching of the mother tongue to meet women in a situation of diversity, in the search for the unanimous desire to learn to read/write, going beyond the mechanical process of decoding, given the challenges posed for emancipatory education in contemporary society.

Keywords: Emancipatory education. Reading. Empowerment. Diversity. EJA. 


\section{LA PEDAGOGÍA LIBERADORA DE FREIRE COMO POSIBILIDAD DEL EMPODERAMIENTO DE LAS MUJERES EN EJA}

\section{RESUMEN}

Este trabajo presenta el resultado de un estudio teórico que forma parte de una investigación desarrollada en la Educación de Jóvenes y Adultos (EJA) y consiste en discutir prácticas lectoras orientadas al empoderamiento de mujeres/estudiantes vinculadas a la escuela primaria en los primeros grados (1er. a 50 año) de EJA. La investigación se justifica por la necesidad de analizar algunos estudios ya realizados por investigadores en esta modalidad de enseñanza, apoyados a la luz de los supuestos de Freire, con el fin de reflexionar sobre las prácticas educativas que se configuran en el universo escolar de EJA. A partir de la metodología de investigación exploratoria, de tipo bibliográfico, los resultados de esta investigación apuntan a la necesidad de acercar a los docentes a la pedagogía del diálogo, la escucha, así como entre los estudiantes, dada la necesidad de prácticas lectoras para atender el empoderamiento. de las mujeres más allá de los muros de la escuela. También apuntan a la enseñanza en lengua materna para encontrar mujeres en situación de diversidad, en la búsqueda del deseo unánime de aprender a leer / escribir, yendo más allá del proceso mecánico de decodificación, dados los desafíos que plantea la educación emancipadora en la sociedad contemporánea.

Palabras clave: Educación emancipadora. Leer. Empoderamiento. Diversidad. EJA.

\section{INTRODUÇÃO}

Este texto versa sobre abordagens reflexivas desencadeadas pela pesquisa teórica realizada no campo da educação básica, particularmente, na Educação de Jovens e Adultos (EJA), e busca discutir os desafios postos à docência no Ensino Fundamental, no que diz respeito ao empoderamento das mulheres que integram as séries iniciais ( $1^{\circ}$ ao $5^{\circ}$ ano) da EJA. Para tanto, busca investigar as questões 
aplicadas a uma pedagogia libertadora orientada à aprendizagem da leitura/escrita, a partir da perspectiva do projeto de educação, sustentado por Paulo Freire, a discutir possibilidades de práticas de leitura voltadas, em particular, ao empoderamento das mulheres nelas inclusas.

A realização deste estudo se deu mediante a execução de uma pesquisa exploratória, bibliográfica e documental, que revisitou estudos sobre as práticas pedagógicas de leitura no campo da EJA, a fim de averiguar os avanços e os dilemas dessa área, o que é recorrente nas produções acadêmicas e quais as lacunas existentes que ainda persistem nas questões aplicadas à educação nessa modalidade de ensino, no que tange às práticas educativas relativas ao enfrentamento das lutas das mulheres, induzidas por uma cultura machista e patriarcal enraizada e presente nas falas das alunas inseridas no ambiente da sala de aula dessa etapa de ensino.

A pesquisa justifica-se mediante as preocupações levantadas, enquanto professora/pesquisadora, no campo da EJA, no que tange à situação das mulheres que, apesar de estarem cotidianamente na escola, enfrentavam severas dificuldades em aprender a ler. Além disso, observavam-se entraves, principalmente, relacionados à ideia de pertencimento à comunidade leitora, pela questão do desconhecimento dessas mulheres de se perceberem como leitoras e cidadãs nas práticas sociais de culturas letradas.

Nesse ensejo, pensando nas necessidades do aprendizado da leitura das estudantes situadas na escola noturna, procuramos investir em uma pedagogia da escuta sensível, sugerida por René Barbier (2002), vinculando-a ao princípio da dialogicidade, defendido por Freire (1994). Nessa escuta sensível, procuramos ouvir as vozes das estudantes da EJA, conhecer suas histórias de vida, suas expectativas quanto à necessidade da leitura em sua realidade social.

Assim, através do conhecimento das narrativas de histórias de vida, explicitadas pelas estudantes nas rodas de conversas desenvolvidas pela pesquisadora, verificamos a necessidade de pensar em uma pedagogia que dialogasse com a situação concreta de opressão, uma "Pedagogia que faça da opressão e de suas causas objeto da reflexão dos oprimidos, de que resultará o seu engajamento necessário na luta por sua libertação, em que esta 
pedagogia se fará e refará" (FREIRE, 1975, p. 43). Desse modo, buscamos discutir no cenário da EJA a questão de gênero, refletindo suas necessidades socioculturais, com o objetivo de reorganizar o conhecimento, dando sentido às atividades de leitura vivenciadas na sala de aula.

Tal compreensão docente reitera as possibilidades de materialização de práticas escolares contra a opressão humana, considerando que o homem começa a pensar acerca da "sua própria capacidade de refletir. Sobre sua posição no mundo. [...] Sobre o seu trabalho no mundo. Sobre seu poder de transformar o mundo" (FREIRE, 1975, p. 117).

Nessa direção, frente aos discursos disseminados na cultura escolar, por um lado, há os discursos que ignoram a presença dos atores/sujeitos sociais nessa etapa educativa como sujeitos aprendentes. Consequentemente, tal percepção dos discentes da EJA passa por mudanças conceituais como fruto das experiências no campo da educação popular, oriundas das contribuições de Freire nesse segmento de ensino.

A partir das contribuições de Paulo Freire para a Educação de Jovens e Adultos no contexto da América Latina e, particularmente, no Brasil, aponta-se para um novo olhar para esta modalidade de ensino. Nelas, busca-se um desenho da problemática da educação no que diz respeito ao direito universal à educação para todos os cidadãos, considerando os aspectos do acesso e a permanência dos estudantes e das estudantes no contexto escolar, de modo a assegurar um ensino de qualidade, a respeitar a identidade da marca da heterogeneidade das turmas em EJA.

Nesse sentido, este trabalho busca dialogar com estudantes reais (no caso, as mulheres da EJA), não concebidos na figura de alunos tradicionalmente presentes na cultura escolar. Pensando em tal diálogo, e a partir do ponto de vista de Soares e Giovanetti (2011, p. 287), ao levantar as questões no campo do direito à educação, compreendemos que "é preciso avançar no campo conceitual, tendo como foco o jovem e o adulto concreto, como sujeito de direitos, e não de favores". Assim sendo, consiste em, particularmente, problematizar a dificuldade enfrentada pelo docente com atuação na EJA quanto às vivências pedagógicas que convergem para assegurar 
o ensino e a aprendizagem da língua materna para os grupos historicamente discriminados e marginalizados, decorrentes de políticas educacionais no Brasil.

Cabe ressaltar que, em seus estudos sobre os saberes necessários para o professor com jovens, adultos e idosos, Romão (2014), ao considerar suas vivências pessoais e como pesquisador freiriano, esclarece que Paulo Freire pontuava sempre que "não deveríamos constituir uma seita, uma confraria de discípulos, nem repetir suas ideias, mas reinventá-las em cada contexto" (ROMÃO, 2014, p. 46). Nesse sentido, há um entendimento de que se pode avançar nos estudos epistemológicos quanto aos modos de produção de conhecimento aplicados ao contexto escolar da EJA, particularmente, no campo da educação libertadora das mulheres.

Nessa direção, indagamos: o que representa, nesse caso, trabalhar com gêneros discursivos, com vistas a dialogar com os atores/sujeitos sociais no aspecto da diversidade na sala de aula da EJA e promover a emancipação social das mulheres? Por onde iniciar as proposições em torno das práticas de leitura nessa modalidade de ensino, visando facilitar o diálogo intercultural que conduz a mulher a refletir sobre suas histórias pessoais de vida como um processo de exclusão social, fruto de negação ao direito constitucional à educação, entre os grupos sociais com breves passagens ou não na escola pública ou privada?

Ao falar de uma educação que respeite a especificidade humana, e considerando as práticas pedagógicas de cunho tradicional disseminadas na cultura escolar, encontramos a presença de discursos que buscam homogeneizar a categoria de aluno da EJA. Sobre isso, é preciso atentar para o aspecto da natureza humana e conceber esse aluno como um ser social aprendente. Desse modo, como já pontuava Freire (2002), faz-se necessário redimensionar a prática escolar como uma ação problematizadora, pensando no sujeito cognoscente inserido no processo de ensino-aprendizagem na contemporaneidade.

Ademais, compreendemos que o acesso às diferentes práticas de usos sociais da leitura e, consequentemente, da escrita não ocorrem unicamente na esfera escolar, tida como espaço relevante das agências de letramento para as camadas populares. Cumpre 
sinalizar que as estudantes da EJA já participam dos usos sociais da leitura/escrita, antes mesmo de sua inserção na instituição escolar.

Nesse sentido, a ideia defendida por Freire (1999) de que ensinar exige reflexão crítica sobre a prática aponta para a necessidade da formação permanente do professor. Partindo dessa perspectiva, acreditamos que a realidade de sala de aula em relação ao ensino de leitura de textos deve ser enxergada não como um produto pronto, acabado, tampouco como uma prática cristalizada, mas passível ao diálogo.

Frente aos desafios da organização de atividades de leitura no espaço da EJA, cumpre ressaltar o que assinala Macário (2018), em relação ao perfil encontrado em suas respectivas experiências educativas em turmas do Ensino Fundamental - anos iniciais ( $1^{\circ}$ ao $5^{\circ}$ ano), quanto à permanência de estudantes em uma mesma turma com as seguintes especificidades: as que não escrevem, mas leem; as que escrevem, mas não leem; e ainda as que nem escrevem e nem leem. Essa realidade encontrada na sala de aula tende a impactar os resultados das práticas de leitura, no sentido de que algum dos grupos citados anteriormente poderá ficar excluído das atividades formuladas para o ensino de leitura.

Diante disso, partindo da realidade escolar e do perfil dos sujeitos sociais da EJA, cabe-nos salientar que discutir a formação de leitores nesta etapa de ensino remete a pensar em um projeto de educação como direito, atentando para um processo educativo que respeite a marca da diversidade situada nos distintos espaços formativos nos quais as estudantes estão inseridas.

\section{Um olhar para a educação libertadora e emancipadora: revisitando teoria e prática no campo da EJA}

Ao refletirmos sobre a educação básica, focalizamos a EJA como um lugar marcado pela diversidade, um aspecto que não pode ser concebido meramente como um empecilho para a alfabetização crítica, mas como parte de um projeto de educação a compreender "o direito à diferença como um enriquecimento educativo e social [...] pautada em ideais democráticos e de justiça social" (IMBERNÓN, 2000, p. 82). 
No campo na cultura acadêmica, é perceptível a observação de um número expressivo de pesquisas que apontam o processo de escolarização das pessoas jovens e adultas tendo por base o "método Paulo Freire" de alfabetização, através do qual o uso do método "palavração ${ }^{3 "}$ buscava contribuir para a conscientização dos sujeitos da EJA.

Para Freire, rememorando a pedagogia libertadora, o encaminhamento da pedagogia consiste na elaboração de uma prática com raízes nos movimentos sociais, fora da escola, como explicitado abaixo:

[...] O enraizamento do paradigma da educação popular nas experiências de movimentos sociais e políticos que se constituíram como núcleos de resistência a regimes ditatoriais, que vigoraram durante os anos 70 em muitos países da América Latina, conferiu-lhe substância e densidade, mas acabou por confiná-lo ao campo ideológico das esquerdas, $o$ que gerou resistências e questionamentos em relação à sua vigência na conjuntura de redemocratização dos regimes políticos do continente. Ao longo dos anos 80 e 90, as mudanças políticas, econômicas, sociais e culturais operadas dos cenários mundial e latinoamericano desencadearam um processo, ainda inconcluso, de refundamentação teórico-prática do paradigma da educação popular. (DI PIERRO; ORLANDO; RIBEIRO, 2001, p. 73).

Freire (2002), apesar de pensar em uma proposta de alfabetização para alunos adultos, tem como base a "perspectiva

\footnotetext{
${ }^{3}$ Segundo o Glossário Ceale, "os métodos de palavração e de sentenciação são agrupados no conjunto de métodos analíticos que partem de unidades de significado. No método de palavração, a ênfase recai na palavra, e não no texto; na sentenciação, a ênfase incide na palavra ou na frase. Ao mesmo tempo em que são incentivadas estratégias de leitura inteligente, a atenção do aluno pode ser dirigida a detalhes da palavra, como letras, sílabas e sons, o que caracteriza este método como analítico-sintético, garantindo o enfrentamento de textos novos". Disponível em: http://ceale.fae.ufmg.br/app/webroot/glossarioceale/verbetes/metodos-de-palavracaoe-de-sentenciacao.
} 
sócio histórica, tendo o materialismo histórico-dialético como pano de fundo e expressa em seus métodos e arcabouço conceitual as marcas de sua filiação dialética" (FREITAS, 2002, p. 22). Nessa direção, o que também se constata é a postura de Vygotsky que, contrapondo-se ao pensamento vigente da época, entende que a aprendizagem não era uma mera aquisição de informações; não acontecia a partir de uma simples associação de ideias memorizadas, mas, sobretudo, tratava-se de um processo interno, ativo e interpessoal.

Cumpre assinalar que o ensino da língua materna, numa perspectiva tradicional, sob o mecanismo metodológico e ideológico do uso de cartilhas, método de silabação, bem como a utilização de textos sem sentido para o aluno inserido nas camadas populares, como já é recorrente nos estudos da EJA, é o reconhecimento de que Freire, ao denunciar práticas tradicionais de leitura na escola, elucidadas a partir do exemplo "vovó e sua uva", numa concepção de alfabetização, contribuiu para trazer à tona a exclusão social, uma vez que essa concepção de ensino percebia que os sujeitos não alfabetizáveis seriam simultaneamente incapazes de pensar.

Desse modo, salientamos que o processo de mudança conceitual epistemológica de alfabetização perpassa a escola e inclui toda a sociedade moderna, com múltiplos letramentos, reunindo práticas sociais discursivas dos usos da escrita e da leitura. Em seus estudos, Fagundes (2010) destaca um dado existente na educação escolar, segundo o qual a concepção de ensino nas turmas de alfabetização pautava-se na memorização-alfabetização, uma situação que remete à história de fracasso escolar, traduzida nos índices de reprovação dos sujeitos sociais que iniciaram o seu processo de escolarização.

Para a pesquisadora Moura (1999), as contribuições de Freire e de Vygotsky identificam os aspectos da teoria e da prática que se articulam e se completam de forma a influenciar o pensamento e as práticas pedagógicas dos professores da EJA. Nessa investigação, a autora constata uma aproximação quanto às preocupações e às inquietações similares em relação à exclusão social e ao analfabetismo. 
Diante do exposto, Moura (1999) salienta que Freire comunga com essa ideia de Vygotsky e pontua que a alfabetização não é um ato meramente mecânico do código alfabético. Nessa interlocução entre os teóricos Freire e Certeau, a autora reitera que os estudos deles se aproximam, já que ambos tratam das práticas culturais como instrumento motivador para o desenvolvimento das ações educativas no interior da escola. No primeiro momento, vê-se a preocupação de Freire na elaboração de um método de alfabetização para adultos, partindo de temas geradores advindos do contexto cultural dos alunos da EJA, através da metodologia do círculo da cultura. Nota-se que Freire se preocupou, inicialmente, com a Educação de Jovens e Adultos, atrelada ao processo de humanização e de conscientização, na qual a educação é ato político, compromisso profissional com a sociedade, "método" e círculos de cultura, como ele destacou em "Educação como prática da liberdade" (FREIRE, 1994).

Trazendo a educação como prática de liberdade, Freire aproxima-se de Certeau, ao defender a ideia da escuta e do diálogo no espaço educativo. Ao pensar a escola além do espaço da cultura da escrita, da fala, Certeau indica a relevância da escuta da alteridade no processo escolar e, endossado pelos trabalhos de Freire, preocupa-se com uma educação dialógica e emancipadora dos sujeitos sociais.

Nesse sentido, Freire (1987) denunciou e questionou a concepção de educação vigente no país, concebida por ele como "educação bancária". Segundo essa concepção educacional, o professor é aquele que detém o conhecimento, o saber que pensa, que dita todo o processo educativo, enquanto os alunos são tidos como "objetos", adereços do espaço de sala de aula. Nessa situação de passividade, o aluno, na condição de objeto, prejudica seu poder criador de refletir sobre sua própria condição de "massificado". Também com os problemas do analfabetismo das camadas populares, "Freire e Vygotsky foram engajados com o seu mundo, o seu tempo e a sua realidade" (MOURA, 1999, p. 23). Segundo Freitas (2002, p.25),

A perspectiva sócio-histórica baseia-se na tentativa de superar os reducionismos das concepções 
empiristas e idealistas. Isso fica evidente no que Vygotsky (1896-1934) assinala como a 'crise da psicologia' de seu tempo, que se debate entre modelos que privilegiam ora a mente e os aspectos internos do indivíduo, ora o comportamento externo. Procura desse modo construir o que chama de uma nova psicologia que deve refletir o indivíduo em sua totalidade, articulando dialeticamente os aspectos externos com os internos, considerando a relação do sujeito com a sociedade à qual pertence. Assim, sua preocupação é encontrar métodos de estudar o homem como unidade de corpo e mente, ser biológico e ser social, membro da espécie humana e participante do processo histórico. Percebe os sujeitos como históricos, datados, concretos, marcados por uma cultura como criadores de ideias e consciência que, ao produzirem e reproduzirem a realidade social, são ao mesmo tempo produzidos e reproduzidos por ela.

Nesse cenário, ao discutir a preocupação de Freire e de Vygotsky aos problemas de sua época, é importante destacar que um primeiro ponto de aproximação entre esses autores situa-se na base epistemológica vinculada à concepção de sujeito histórico-cultural subjacente às duas teorias. Sendo assim, é evidente que o que caracteriza a cultura escolar é um quadro de tensões e desafios na sala de aula configurada com sujeitos sociais dotados de uma diversidade, cuja prática escolar não enxerga a mulher como fruto de uma cultura advinda de discursos da invenção do patriarcalismo, ideia machista, como uma pessoa não pertencente ao mundo da escola.

Isso ocorre pelo fato de a escola trilhar pelos encaminhamentos curriculares centrados em propostas pedagógicas que se dizem para a demanda social em EJA, prevalecendo um ensino pautado nos princípios norteadores do ensino regular, resultando em quadros de reprovações e abandono da sala de aula por parte do aluno. Quanto ao problema de formação docente para atuação na EJA, Freitas e Cavalcante (2014, p. 94) advertem:

As políticas públicas de leitura têm atuado quase sempre fragmentadas, não incentivando uma 
formação continuada específica para os/as educadores/as e para aqueles/as que são responsáveis pelas salas de leitura, que em sua maioria são professores/as readaptados, em desvio de função da regência de sala de aula. Focalizam apenas a necessidade das escolas e dos/as professores/as incentivarem o gosto pelo ato de ler, diante de um acervo predominantemente de livros didáticos. Outra lacuna existente nas escolas, quando da realização de ações para se despertar o prazer pela leitura, é que não se tem explícito a definição sobre que tipo de leitor se pretende formar. Não se reflete sobre os aspectos referentes aos eventos e práticas de letramento que estão ocorrendo nas salas de aula, da mesma forma, não se enfatiza a importância de os professores conhecerem as teorias sobre processamento de leitura, conhecimento esse necessário, mas que na sua maioria, não tiveram na sua formação inicial.

Diante do exposto, através dos resultados de pesquisa dos autores supracitados, observa-se uma lacuna existente entre o proclamado pelas políticas públicas de incentivo à leitura, paralelamente ao desafio da formação de professores frente ao que preconiza o Parecer do MEC: "A rigor, as unidades educacionais da EJA devem construir, em suas atividades, sua identidade como expressão de uma cultura própria que considere as necessidades de seus alunos e seja incentivadora das potencialidades dos que as procuram" (BRASIL, 2000, p. 35). O que predomina são práticas pedagógicas a favorecer a exclusão do aluno do direito de aprender na escola, distanciando-o de um projeto educacional voltado para a emancipação humana.

Desse modo, falar de emancipação humana é procurar o seu contraditório: a opressão, como assinala Freire (1975), favorece, no campo ideológico, reflexões críticas em torno de práticas pedagógicas capazes de contribuir para a construção de sujeitos ativos e participativos na sociedade. Sendo assim, ao discutir o papel da prática educativa com fins de emancipação humana, convém destacar as ideias de Santos (2010, p. 242): 
[...] do ponto de vista das relações entre as particularidades únicas das subjectividades individuais e a abstracção e universalidade das categorias da sociedade política, a eficácia subjectiva da classe operária é, ao nível da emancipação, semelhante à da cidadania liberal, ao nível da regulação. Ou seja, a subjectividade colectiva da classe tende igualmente a reduzir à equivalência e à indiferença às especificidades e as diferenças que fundam a personalidade, a autonomia e a liberdade dos sujeitos individuais.

Cabe aqui registrarmos que tal perspectiva defendida por Santos (2010), sob o enfoque sociológico, já era observada nas contribuições freirianas, cujo pensamento assinalava a ação da educação sob o olhar da transformação da sociedade. Evidentemente, tais mudanças sociais, conforme Freire (1994), só eram possíveis se as pessoas tomassem consciência de sua condição de oprimidas, o que implica uma ação dialógica de mudança de consciência ingênua para uma consciência crítica, passando a ser sujeitos de sua própria história.

A EJA deve ser pensada como um modelo pedagógico próprio, com o objetivo de criar situações de ensino-aprendizagem adequadas às necessidades educacionais desse público, englobando as três funções citadas no Parecer 11/00 da CEB: a função reparadora, caracterizada pela entrada no circuito dos direitos civis e pela restauração de um direito negado, o direito a uma escola de qualidade e o conhecimento de igualdade de todo e qualquer ser humano; a função equalizadora, centrada em um atendimento pleno e legal a trabalhadores e a tantos outros segmentos da sociedade, possibilitando-Ihes a reentrada no sistema educacional; e a função permanente, voltada para uma educação de jovens e adultos que deve dar condições ao aluno para atualizar conhecimentos por toda a sua vida.

Obviamente, a função permanente da EJA, que se pode denominar de qualificadora, mais do que uma função, diz Soares (2002), é o próprio sentido da EJA. Diante disso, observamos, também, que Ireland (2003, p. 3-4) já criticava o modelo de EJA "a ser tratada como em muitas instâncias já o foi, como uma atividade 
marginal a ser desenvolvida por amadores". Enfatizamos que tal perspectiva educativa para essa modalidade de ensino deve ser pensada tendo em vista criar espaços educativos, principalmente dentro e fora da escola, a oferecer práticas de letramentos de modo a pensar uma proposta pedagógica de qualificação de vida para todos aqueles que acorrem à escola.

\section{Os atores/sujeitos sociais da EJA}

Em tempos passados na educação em território brasileiro, o perfil dos estudantes em contexto alfabetizador da EJA era caracterizado segundo os discursos disseminados pela cultura escolar, como uma demanda social constituída unicamente por pessoas adultas. Ocorre que tal caracterização escolar dessa etapa de ensino, desde o início da segunda década deste século, passa por mudanças perceptíveis nos contextos escolares. Como salienta Macário (2018), se anteriormente a sala de aula era composta basicamente por pessoas adultas e o interesse de estudar encontrava-se preponderantemente associado à alfabetização e, consequentemente, tal realidade escolar tende a ser alterada; essa transformação tem ocorrido, notadamente, conforme os estudos sinalizados por essa autora, devido à presença dos estudantes adolescentes e jovens com passagens no Ensino Fundamental regular, que exigem ações didáticas mais comprometidas com perspectivas de inserção social em que o ensino da língua materna tem espaço central.

Assim sendo, ao percorrer os caminhos da diversidade em EJA, é possível observar pesquisas no campo desta modalidade de ensino pautadas na diversidade, no que diz respeito às singularidades dos alunos em sala de aula desta etapa de ensino, como sujeitos de aprendizagem. Nessa direção, Paiva (2005, p. 10) percorre a questão centrada na EJA, enfatizando o viés do "direito, concepções e sentidos", e já chamava a atenção para a situação do aluno que é "empurrado para EJA". Cabe destacar que a preocupação deste estudo recai na crítica de que não basta assegurar ao aluno em situação de insucesso escolar o acesso à escola, a escolarização através de certificação, mas, deve-se, sobretudo, refletir a inclusão 
escolar desse sujeito social, considerando que tal mecanismo usado pela educação escolar resulta em um dilema, uma vez que tende a ser insuficiente a escola incluir o aluno para excluí-lo do sistema escolar.

Nessa perspectiva, ao tratar sobre a escola e a exclusão, reiteramos para o que chama a atenção Dubet (2003, p. 36), ao elucidar que

[...] os alunos com dificuldades são orientados para trajetórias escolares mais ou menos desvalorizadas no interior de uma hierarquia extremamente rígida, que impede, quase por completo, o retorno para as carreiras honrosas ou prestigiadas.

Desse modo, considerando o contexto da EJA, no que tange à juventude no espaço escolar, Dayrell (2007), em suas pesquisas sobre a escola e os jovens, reforça que a dificuldade na trajetória escolar dos jovens na escola encontra-se vinculada ao impasse, por um lado, envolvendo o que é ensinado na escola para o aluno e, por outro lado, o que envolve os sentidos atribuídos pelos alunos. Como tais conteúdos não apresentam sentido para o aluno, este demonstra desinteresse. Segundo o autor, trata-se de um desinteresse pelos estudos, mas não a incapacidade desse aluno em aprender.

Candau (2008) traz uma abordagem reflexiva sobre a relevância da questão cultural voltada ao campo da educação. Nessas reflexões, direcionadas à ação docente na escola, concordamos com assertiva no sentido de um projeto de educação a promover uma educação para o reconhecimento do "outro", para o diálogo entre os diferentes grupos sociais e culturais, e se encontra orientada para a construção de uma sociedade democrática, plural, humana, que articule políticas de igualdade com políticas de identidade. Assim, menciona:

Algumas doutrinas pedagógicas concorreram para acentuar atitudes equivocadas por parte de educadores na escola. Teorias que afirmam a carência cultural, ainda que rejeitadas atualmente, deixaram marcas na prática pedagógica, justificando o fracasso escolar única e 
exclusivamente pela 'falta de condições' dos alunos. Esse tipo de estigma 'contagiou' professores e escolas. Por ocasião do processo de ampliação das oportunidades educacionais, sobretudo a partir da década de 70, tornou-se comum certa argumentação que vinculava, indevidamente, a queda da qualidade do ensino ao acesso das camadas populares a uma escola que fora, até então, explicitamente seletiva. (BRASIL, 1997, p. 126).

Nesse sentido, em comum acordo com tais argumentos, é importante que se destaque que o trabalho educativo na sala de aula, especificamente, na modalidade de ensino da EJA, é momento crucial para levar em consideração o diálogo entre as culturas, considerando que na sala de aula há diferentes estudantes, com distintas expectativas e histórias de vida. Faz-se necessário, portanto, ressignificar as ações educativas voltadas para o ensino da língua materna, sob o foco da leitura, em diferentes contextos socioculturais, de modo a incluir todos os diferentes grupos sociais situados na sala da aula da EJA.

Nesse debate, cabe destacar as orientações de Paulo Freire e Ira Shor em "Medo e Ousadia: o cotidiano do professor" (1986), no tocante à preocupação de uma educação a pensar ações educativas a libertarem os sujeitos sociais nelas inclusas. Como examinam os autores,

A educação libertadora é, fundamentalmente, uma situação na qual tanto os professores como os alunos devem ser os que aprendem; devem ser os sujeitos cognitivos, apesar de serem diferentes. [...] exatamente por isso, o contexto da transformação não é só a sala de aula, mas encontra-se fora dela. Se o processo for libertador, os estudantes e os professores empreenderão uma transformação que inclui o contexto fora da sala de aula. (FREIRE; SHOR, 1986, p. 27).

Diante disso, acreditamos que a escola não pode desconsiderar os usos sociais da leitura no cotidiano do aluno, e considerando o ensino em processo de alfabetização/letramento, em 
turmas de alfabetização na EJA, entendemos ser mais produtivo levar em consideração uma prática de sala de aula na qual o currículo venha a atender as especificidades dessa demanda escolar, levando em consideração os aspectos motivacionais que resultaram na busca à escola.

Práticas de leitura na EJA: discutindo o empoderamento das mulheres

Nesta seção, buscamos refletir a situação das mulheres na EJA, considerando as experiências desencadeadas no contexto escolar desta etapa de ensino, aqui discutindo os resultados de pesquisas desenvolvidas pela pesquisadora correlacionadas às práticas de letramento, reunindo mulheres no âmbito do ensino fundamental no horário noturno, em escolas da rede pública municipal de uma cidade do estado da Paraíba. Para tanto, apresentaremos, neste trabalho, um recorte de algumas histórias de vida das estudantes a contribuir com o objetivo desta pesquisa, no que concerne ao empoderamento das estudantes em relação à aprendizagem da competência leitora, a transitarem de forma bem-sucedida na leitura de textos que circulam no âmbito escolar e fora dele.

Nessa direção, ao discutirmos sobre o empoderamento das mulheres nos espaços da EJA, a partir das questões levantadas na introdução deste artigo ( $\mathrm{O}$ que representa trabalhar com gêneros discursivos, com vistas a dialogar com os atores/sujeitos sociais no aspecto da diversidade na sala de aula da EJA e promover a emancipação social das mulheres? Por onde iniciar as proposições em torno das práticas de leitura nessa modalidade de ensino, visando facilitar o diálogo intercultural que conduz a mulher a refletir sobre suas histórias pessoais de vida como um processo de exclusão social, fruto de negação ao direito constitucional à educação, entre os grupos sociais com breves passagens ou não na escola pública ou privada?), o estudo aponta para os conflitos apontados por essas estudantes, da questão da necessidade da leitura para resolver os seus problemas cotidianos.

Freire e Shor (1986), para tratar de uma pedagogia dialógica, utilizam o termo empowerment [empoderamento] no contexto da 
educação. Os educandos e as educandas, ao se perceberem como sujeitos que entendem e refletem de forma crítica sobre sua realidade de opressão e desvantagem social, econômica e política, anseiam em modificar radicalmente essa opressão. No decorrer desse processo, eles são capazes de notar o poder existente em seu grupo e nas reações externas e, assim, alcançam os princípios do empoderamento como as lutas de classe social (FREIRE; SHOR, 1986).

Assim, para compreender o espaço da EJA como sendo apropriado para tratar a questão do empoderamento das mulheres, segundo a perspectiva freiriana, destacamos que o empoderamento, por si só, não é suficiente para a construção de uma mudança no contexto social, mas torna-se um passo significativo para o processo de mudança social. Sendo assim, as mulheres empoderadas são sujeitos sociais e emancipadas, protagonistas de sua própria história, capazes de perceber, refletir e compreender a sua situação social no sentido de, individual e/ou coletivamente, produzirem mudanças significas para a construção de uma sociedade mais humana e democrática.

Nessa perspectiva, a sala de aula passa a ser palco de um universo de alunos com ritmos diferenciados de aprendizagem, restando ao professor se "virar". Essa realidade de sala de aula no contexto da EJA aponta para o fato de que a escola, além de incluir os múltiplos alunos, categorizados na sua maioria por uma diversidade de identidades culturais, geracionais, étnico-raciais, de gênero, oriundos do espaço rural/urbano, de inserção no mundo do trabalho, de trajetórias e de expectativas motivacionais, precisa lançar-se ao desafio de, além de alfabetizar, focalizar o desenvolvimento de sujeitos sociais leitores para o atendimento das capacidades e das habilidades exigidas na contemporaneidade.

Entendemos que a experiência com a leitura de textos que circulam fora da sala de aula oportuniza ao professor criar situações de atividades de leitura com sentidos para a vida do alunado, haja vista tratar de uma temática de interesse da coletividade, reforçando o aspecto da inclusão social. Como sustenta Strey (2012, p. 218), é necessário definir a interface em que se trabalha a leitura, de modo que "Se a área de interface é a social, podemos entender leitura como 
uma prática de inclusão social, em que se trabalha com conceitos de capacidade crítica e de exercício da cidadania".

Nesse contexto, corroborando a perspectiva da leitura à luz da inclusão social, buscamos, neste estudo, apresentar alguns casos de alunas da EJA, desencadeados pelas experiências da professora/pesquisadora já fomentadas em percursos anteriores no ambiente escolar, convivendo cotidianamente com as estudantes. Vale assinalar que entre os distintos grupos sociais que se encontravam nas turmas das séries iniciais de Ensino Fundamental, trazemos histórias de vida que dão voz ao alunado da EJA, em particular das mulheres, abarcando práticas de leitura construídas com a representação de sentidos para além dos muros da escola.

Como já vimos, no que diz respeito às práticas educativas, na perspectiva freiriana, é importante atentar para o fato de que a experiência de vida dos sujeitos sociais da EJA confere a essa modalidade de escolarização básica práticas de letramento como premissa de uma prática contextualizada, numa dimensão social, ou seja, uma prática de letramento capaz de usar a leitura e a escrita como meio de tomar consciência da realidade e de transformá-la.

Frente ao exposto, Freire (1999) vê o letramento como sendo ou de libertação do homem ou de sua "domesticação", dependendo do contexto ideológico em que ocorre, e alerta para a sua natureza inerentemente política, defendendo que seu principal objetivo deveria ser o de promover a mudança social.

Para efeito de visualização, destacamos a participação de quatro atores/sujeitos sociais que contribuíram significativamente para pensar os sentidos que ajuízam a leitura dos textos nos espaços interiores e externos à escola. O primeiro caso refere-se à performance da estudante de 33 anos, que busca a escola para aprender a ler após um período de negação ao direito subjetivo à educação, por uma questão de dominação da cultura machista (BOURDIEU, 2005), como podemos observar na fala da aluna T (apud MACÁRIO, 2014, p. 39.:

O meu esposo dizia 'tu não vai aprender não'. Aí foi passando o tempo, aí ele disse, e eu sempre dizia '[...] me deixa ir pra escola, eu quero estudar', aí ele dizia 'não, você não vai não, quem já viu mulher 
casada estudar?', aí eu disse 'pronto, eu já vejo um bocado aí estudando', aí foi passando o tempo, foi passando o tempo, aconteceram muitas coisas, né, aí eu disse '[...], agora eu vou estudar', aí ele disse 'é, vá, eu vou deixar, vá simbora fazer a matrícula'. Aí eu fiz a matrícula um ano, não deu certo, aí eu digo 'pronto, era só o que me faltava'. Passou um tempo, aí eu digo 'Agora eu vou lá no colégio e não vou mais fazer matrícula com ninguém. Eu vou diretamente lá no colégio que é onde se faz a matrícula de verdade'. Aí chegou o dia e fui-me embora e hoje tô aqui. E tô aprendendo. E quero aprender mais e mais. É pouco ainda porque ainda eu erro as palavras quando eu vou escrever, mas é perseverando que a gente chega lá. Tá bom, professora? (risos).

Nesse cenário, observamos que a fala da aluna reflete as situações de opressão a que são submetidas as mulheres que tiveram seus direitos negados por uma prática cultural muito forte de exclusão das mulheres, enraizada nas culturas dominantes. Vê-se, portanto, protagonistas de histórias reais, particularmente, de estudantes/mulheres, que revelam uma trajetória de experiências de negação ao direito à educação formal, de desigualdade social e de exclusão social. Tal situação de negação do direito à educação vivenciada pelas mulheres revela resquícios da concepção machista, signo de uma sociedade patriarcal, aliada a questões de caráter colonial do binarismo dominante/dominado, dificultando para essas mulheres na sua formação profissional.

A referida aluna, de 33 anos, no intuito de aprender a ler e a escrever, sob o olhar de uma educação emancipadora, apesar do enfrentamento com o seu esposo, conduzia toda noite à sala de aula uma filha pequena, como condição para estudar mais tranquila. Assim, o percurso trilhado por essa estudante era construído por uma participação assídua das aulas em todas as noites, de segunda à sexta-feira, apesar da resistência do seu esposo, atribuída de forma preconceituosa e machista em não permitir que ela estudasse naquela faixa etária. Nesse primeiro caso citado de busca do empoderamento das mulheres, observamos que nos espaços sociais, fora da escola, essa estudante conseguia estabelecer um diálogo 
crítico junto ao seu esposo, da importância dos estudos para o empoderamento da dimensão econômica. A estudante fazia uso de argumentos críticos, justificando a necessidade de aprender a usar o computador em seus negócios (mercadinho). O que estava implícito nessa negociação era o seu desejo pessoal de aprender a ler e a escrever para retirar sua carteira de habilitação, ser uma motorista, ou seja, ter autonomia de se deslocar sem depender exclusivamente do seu marido.

Já o segundo caso (aluna de 65 anos) reforça um pensamento machista muito presente na cultura das camadas populares, de um discurso de negação das mulheres de estudarem, igualmente como os do sexo masculino. Neste estudo, encontramos a presença na sala de aula de uma mulher que não tinha desistido do sonho de frequentar os bancos escolares. Nesse caso, a negação da escola vem por parte da família, particularmente, de ordem dos pais, em destaque da figura do "chefe da família", ou seja, da pessoa do pai que não aceita o direito do desenvolvimento intelectual de sua filha, com a valorização dos discursos de que filha de agricultores não precisa estudar para escrever cartas para namorados.

Segundo a percepção da aluna de 65 anos, na época da sua juventude, eram disseminados nas práticas culturais valores ideológicos preconceituosos contra a mulher, pautados na concepção de que "mulher não podia estudar, para não escrever cartas para o namorado". Não estudou porque o pai não deixou, e não porque teve de trabalhar na roça.

Nessa situação de opressão feminina descrita, relacionada a uma história de negação, de exclusão, de negação ao direito à educação escolar, salientamos o que discorre Albuquerque Junior (2013), em sua obra intitulada "Nordestino: invenção do 'falo' uma história do gênero masculino" (1920-1940), destacando a cultura patriarcal muito presente na nossa região: "A própria educação feminina deveria tornar-se mais prática, voltada para as atividades que eram destinadas a seu sexo, ou seja, era preciso educar as moças para serem boas donas de casa, saberem bem administrar a economia doméstica" (ALBUQUERQUE JUNIOR, 2013, p. 122). Um modelo de educação disseminado nas práticas culturais que impediam as mulheres de estudar, de opinar, de expressar seus 
sentimentos e opinião. Geralmente, ouvia-se que "lugar da mulher era na cozinha", uma situação de opressão feminina que ainda encontramos na realidade social das estudantes da EJA.

Em relação ao terceiro caso, citamos a aluna de 27 anos que, na condição de uma consumidora, necessitava de saberes no campo da alfabetização matemática a lidar com capacidades e habilidades pertinentes ao campo do raciocínio lógico, no que tange ao uso dos cálculos matemáticos no cotidiano das pessoas. Para tanto, observase que a partir da realização de mediação didática na sala de aula da EJA, proposta por Macário (2014), com base na leitura de encartes publicitários envolvendo gêneros alimentícios de supermercados em promoção, com destaque na problematização de situações problemas envolvendo as quatro operações fundamentais, encontramos satisfação leitora nesse tipo de atividade realizada diariamente por parte daqueles sujeitos sociais que estavam situados nesta pesquisa.

A aluna de 27 anos relata que tal procedimento didático vivenciado na sala de aula permitiu um avanço na sua aprendizagem envolvendo leituras matemáticas e, através do seu progresso em relação aos cálculos matemáticos, destaca uma situação que a incomodava na sua vida pessoal em relação a uma compra realizada com o auxílio de uma vizinha. Na opinião dessa aluna, o seu desenvolvimento nas aulas de leitura, no campo da matemática, permitiu enxergar:

Fiquei pensando nas contas de menos que a professora ensinava na sala de aula. Aí vi que tava sendo enganada pela minha vizinha. Tinha pedido pra ela comprar meu celular no cartão dela, dividido em 10 vezes de $R \$ 28,00$, só que dava $R \$ 50,00$ e não recebia troco. Aí como eu aprendi, fui cobrar meu troco e ela fez: 'Como foi que tu descobrisse? Se tu não sabe ler nem escrever!'. Aí eu fiz: 'Ah minha filha, eu aprendi!' (apud MACÁRIO, 2014, p. 44-45).

Nesse sentido, torna-se relevante focar na atividade de leitura e nos diferentes modos de ser leitor, o que implica buscar compreender quem são os alunos dessas turmas; saber o que leem e o que não leem, e os motivos desse distanciamento com a leitura; 
sondar o que fazem e o que pensam; o que esperam e o que sentem diante do conhecimento.

Dos diversos relatos acompanhados neste estudo, cabe destacar o último caso da aluna que já exercia no espaço externo escolar a função de trabalhadora no campo dos serviços públicos de limpeza municipal, atuando como gari, justamente, no lugar onde se localizavam as três bancas de revistas visitadas na pesquisa de Macário e Rodrigues (2021). Essa aluna, de 42 anos, já deixava claro nos encontros de leitura em sala de aula a sua não identificação como leitora de revistas em âmbito social. Quando questionada, em dias anteriores nas aulas, se não tinha vontade de entrar na banca para folhear tais revistas, verbalizou que passava o dia todo ali, mas "limpando, isto é, trabalhando" e não vendo a hora de "voltar para casa e arrumar as coisas para vim para escola estudar".

Essa aluna não se via leitora fora do ambiente escolar, estava centrada na leitura na escola. Porém, com o desenvolvimento das rodas de conversa, realizadas na sala de aula, atreladas aos diversos relatos das novas descobertas feitas pelo "encanto da leitura", nos mais diversos contextos sociais, inclusive na banca de revistas onde os alunos da EJA estiveram envolvidos com a leitura efetiva, sócioculturalmente evidenciada pelo ato de ler, ela ora profissional ora aluna expressou que, até então, não tinha observado que poderia também ter acesso àquele ambiente de leitura: "via revistas, às vezes, jogadas no chão, as quais faziam a coleta de lixo", e pouco refletia, observava, "eram lixo, não revistas". E assim seguia, vendo possíveis leituras como lixo por não ter a leitura como função social. Uma prática que adquiriu proporções positivas e momentos encorajadores, como quando essa aluna relata o quanto é emocionante poder decifrar o código escrito, chorando e sorrindo, ao mesmo tempo, por se revelar, descobrir-se leitora.

Freire (2002, p. 92) afirma "que a melhor maneira que nós temos de pensar mais ou menos certo é pensar na prática e saber que esta prática não é individual, mas social". Assim, atentos para o que esse autor propõe, observamos ainda que tal reflexão da prática educativa se faz necessária, inclusive, no que diz respeito aos espaços e ao tempo para tal ação escolar e, sobretudo, aos apoios e incentivos 
técnicos aos professores e aos alunos, proporcionais aos desafios que eles têm de enfrentar diariamente na EJA.

Diante disso, a pesquisa desenvolvida nos instiga a refletir que a prática de leitura na perspetiva da formação de leitores críticos na EJA perpassa pela formação inicial e, principalmente, continuada, cujo encaminhamento das ações teórico-metodológicas nos possibilita aproximar a teoria da prática com mais amadurecimento profissional.

É importante salientar que a prática educativa evidenciada na escola, em relação ao ensino da leitura, se contradiz. Como sustenta Rodrigues (2012), a leitura do mundo é essencial para a vida das pessoas, considerando sua atuação nos diferentes setores na sociedade. E, consequentemente, por esta razão, faz-se necessário pensar os entraves que dificultam a compreensão da leitura na atualidade, de modo a contribuir para a formação de cidadãos, de mulheres que dialogam com uma variedade de textos, de práticas sociais e que constroem suas próprias identidades.

\section{CONSIDERAÇÕES FINAIS}

Em linhas gerais, defendemos a formação de professores com atuação na EJA, em cenário de educação contemporânea. É oportuno ressaltar que a ação docente não pode servir de modismo ou de mudança nos discursos, mas, sobretudo, para contar com o estabelecimento de novas interlocuções, de empoderamento das mulheres, incluindo o respeito à especificidade da modalidade educativa quanto ao uso de metodologias capazes de atender as peculiaridades dos contextos históricos dos atores sociais da EJA. Por essa razão, comungamos com as concepções freirianas, cuja reflexão teórico-metodológica nos permitiu analisar que tipo de prática de alfabetização e de letramento encontra-se a serviço da "libertação dos sujeitos" inseridos na educação básica do país.

A partir das discussões suscitadas neste trabalho, no que se refere à Educação de Jovens e Adultos (EJA), entre os pontos considerados significativos nesta pesquisa, destaca-se o avanço no aprendizado da compreensão leitora crítica de mulheres pelo uso de uma pedagogia favorável ao empoderamento, o que sinalizou para a ênfase numa formação docente que priorize o olhar para as alunas 
em situação de insucesso escolar, problematizando o contexto de situação de opressão frente às suas insatisfações de frequentarem as aulas enquanto sujeitos de direitos em situação de igualdade com os demais grupos sociais, como protagonistas de suas próprias histórias de vida e, principalmente, como produtoras de conhecimentos nos distintos espaços, dentro ou fora da escola.

\section{REFERÊNCIAS}

ALBUQUERQUE JÚNIOR, D. M. Nordestino: invenção do "falo" uma história masculina (1920-1940). 2. ed. São Paulo: Intermeios, 2013. (Coleção Entregêneros).

BARBIER, R. A pesquisa-ação. Tradução de Lucie Didio. Brasília,DF: Plano, 2002. (Série Pesquisa em Educação, v. 3).

BOURDIEU, P. A Dominação Masculina. 4. ed. Rio de Janeiro: Bertrand Brasil, 2005.

BRASIL. Proposta Curricular do MEC/Ação Educativa: $1^{\circ}$ Segmento do Ensino Fundamental - EJA. Brasília, 1997.

BRASIL. Conselho Nacional de Educação. Parecer CEB n. 11/2000. Diretrizes Curriculares para a Educação de Jovens e Adultos. Brasília: MEC, maio 2000.

CANDAU. V. M. Direitos humanos, educação e interculturalidade: as tensões entre igualdade e diferença. Revista Brasileira de Educação, v. 13, n. 37, jan./abr. 2008.

DAYRELL, Juarez. A escola "faz" as juventudes? Reflexões em torno da socialização juvenil. Educação e Sociedade, Campinas, v. 28, n. 100, especial, p. 1.105-1.128, out. 2007.

DI PIERRO, C.; ORLANDO, J.; RIBEIRO, V. M. Visões da educação de jovens e adultos no Brasil. Cadernos Cedes, ano XXI, n. 55, p. 58-77, nov. 2001.

DUBET. F. A escola e a exclusão. Cadernos de Pesquisa, n. 119, p. 29-45, jul. 2003. 
FAGUNDES, T. B. O aluno e a sua escrita: a construção do aluno ideal e a negação do aluno real. In: ENCONTRO NACIONAL DE DIDÁTICA E PRÁTICA DE ENSINO, 15., Belo Horizonte. Anais [...] Belo Horizonte, MG: UFMG, 2010, p. 2-12.

FREIRE, P. Pedagogia do oprimido. Rio de Janeiro: Paz e Terra, 1975.

FREIRE, P. Educação e mudança. 13. ed. Rio de Janeiro, RJ: Paz e Terra Educação, 1987.

FREIRE, P. Educação como Prática da Liberdade. Rio de Janeiro: Paz e Terra, 1994.

FREIRE, P. Pedagogia da autonomia: Saberes necessários à prática educativa. São Paulo: Paz e Terra, 1999.

FREIRE, P. Educação: o sonho possível. In: BRANDÃO, Carlos R. (Org.). $O$ Educador: vida e morte. Rio de Janeiro: Graal, 2002, p. 91101.

FREIRE, Paulo; SHOR, Ira. Medo e ousadia: o cotidiano do professor. 5. ed. Rio de Janeiro: Paz e Terra, 1986.

FREITAS, M.Q.; CAVALCANTE, V. C. Leitura na Educação de Jovens e Adultos e a formação de leitores. Perspectiva, Florianópolis, v. 32, n. 1, 93-109, jan./abr. 2014.

FREITAS, M. T. A. A abordagem sócio-histórica como orientadora da pesquisa qualitativa. Cadernos de Pesquisa, São Paulo, n. 116, p. 21-40, jul. 2002.

IMBERNÓN, F. Educação para o século XXI: os desafios do futuro imediato. Porto Alegre: Artmed, 2000.

IRELAND. T. D. Fundamentos políticos da Educação de Jovens e Adultos. São Paulo: USP/Faculdade de Educação, 2003.

MACÁRIO, R. de O.; RODRIGUES, L. P. A leitura na Educação de Jovens e Adultos: uma experiência pedagógica para a formação de leitores mediada com revistas. Revista de Educação, PUCCampinas, v. 26, p. 1-17. 2021. 
MACÁRIO, R. de O. Práticas de letramento na Educação de Jovens e Adultos: a revista como possibilidade de formação do leitor crítico. 2014. 116f. Dissertação (Mestrado Profissional em Formação de Professores) - Universidade Estadual da Paraíba, Campina Grande, 2014.

MACÁRIO, R. de O. Leitura e processos de formação de leitores em EJA. Rio de Janeiro: UERJ, 2018. 243f. Tese (Doutorado em Educação) - Faculdade de Educação, Universidade do Estado do Rio de Janeiro. Rio de Janeiro, Brasil, 2018.

\section{MOURA, T. M. de M. A Prática Pedagógica dos Alfabetizadores} de Jovens e Adultos: contribuições de Freire, Ferreiro e Vygotsky. Maceió: EDUFAL, 1999.

PAIVA, Jane. Educação de Jovens e Adultos: direito, concepções e sentidos. Niterói: UFF, 2005.

RODRIGUES, L. P. Atitude responsiva na interação verbal: a relevância do contexto para a significação/compreensão leitora. In: XAVIER, Manassés Morais. (Org.). Linguística Aplicada em Foco: Práticas e Propostas de Ensino de Língua Materna na Formação Continuada de Professores. 1. ed. Campina Grande: Realize Editora, 2012, v. 1, p. 637-649.

ROMÃO, J. E. Paulo Freire e a Educação de Jovens e Adultos. EJA em debate, Florianópolis, ano 3, n. 4, jul. 2014.

SANTOS, B. de S. Pela mão de Alice: o social e o político na pósmodernidade. 13. ed. São Paulo: Cortez Editora, 2010.

SOARES, Leôncio; GIOVANETTI, Maria Amélia Gomes de Castro; GOMES, Nilma Lino. Diálogos na Educação de Jovens e Adultos. 4 ed. Belo Horizonte: Autêntica, 2011.

STREY, C. O objetivo de leitura em uma interface psicolinguísticapragmática. Trabalhos de linguística Aplicada, v. 51, n. 1, p. 217233, 2012.

Submetido em: Julho/ 2021.

Aceito em: Agosto/ 2021. 